\title{
Malignant cardiac tumours
}

\author{
Tumores cardíacos malignos
}

Paulo Ruiz Lucio de LIMA ${ }^{1}$, Pedro Luís Reis CROTTI ${ }^{2}$

RBCCV 44205-671

\begin{abstract}
Neoplasms of the cardiovascular system are rare pathologies associated with non-specific signs and symptoms. Cardiac neoplasms should be considered when treating cardiac arrhythmia, Hiss-Purkinje conduction system dysfunction and ischemic syndromes. Tumours of the cardiac muscle are rhabdomyosarcomas that develop frequently in the left chambers, mainly the left ventricle.

Among endovascular tumours, the most common one is the myxoma of left atrium and its variant forms. Metastatic tumours of the heart, among them the malignant melanoma, affect the right ventricle more commonly (anterior wall and septum, with invasion of the left ventricle), in the nondisseminated form. Late diagnosis results in high morbidity
\end{abstract}

Dr. Paulo Ruiz Lucio de Lima

Hospital Amecor - University of Cuiabá (UNIC)

Av. Historiador Rubens de Mendonça, 898

Bairro Baú

78008-000 - Cuiabá - Mato Grosso

Dr. Pedro Luís Reis Crotti

Hospital Amecor -Federal University of Mato Grosso (UFMT)

Av. Historiador Rubens de Mendonça, 898

Bairro Baú

78008-000 - Cuiabá - Mato Grosso

Correspondence address:

Dr. Paulo Ruiz Lucio de Lima

Rua Ana Maria $\mathrm{n}^{\circ} 47$

Condomínio Jardim Itália II - Bairro Jardim Itália

78060-755 - Cuiabá - Mato Grosso

Contact telephone: 0xx65 - 664-3139 (residential)

065 9971-1640 (cellular)

E-mail: pruizll@terra.com.b

Work presented to the Brazilian Society of Cardiovascular Surgery

for the Cardiovascular Surgery specialist certificate in March 2003. and mortality rates whether surgical treatment is given or not. The authors describe the case of a right ventricle melanoma patient, comparing the diagnostic approach and treatment with published data. The treatment of choice of cardiac muscle malignant tumours (both primary and metastatic) is non-conclusive according to our literature review. Due to the low incidence of this pathology, the authors suggest additional meta-analytic studies should be performed to establish diagnostic and therapeutic criteria for the malignant tumours of the heart.

Descriptors: Heart neoplasm. Melanoma. Myxoma. Arrhythmia. Cardiac surgical procedures. 


\begin{abstract}
Resumo
Os tumores do sistema cardiovascular são afecções raras. Manifestam-se por sinais e sintomas inespecíficos, na maioria das vezes. $O$ tratamento de alterações de ritmo cardíaco, das doenças que acarretam disfunção no sistema de condução Hiss-Purkinje e das síndromes que podem acometer o coração (isquêmica, particularmente) devem levar em consideração a possibilidade de neoplasias cardíacas. Os tumores do músculo cardíaco são os rabdomiossarcomas, que se desenvolvem com maior freqüência nas cavidades cardíacas esquerdas, principalmente no ventrículo esquerdo. Dentre os tumores endovasculares, o mais freqüente é o mixoma de átrio esquerdo e suas possíveis variantes. Os tumores metastáticos do coração, entre eles o melanoma maligno, são descritos com maior freqüência acometendo o ventrículo direito (parede anterior e septal, com invasão do ventrículo esquerdo), nas
\end{abstract}

\section{INTRODUCTION}

The study of carcinogenesis currently includes many factors. Extrinsic factors to the organism (predisposing environmental agents) and intrinsic factors related to the development of neoplasias (genetic predisposition, prooncogenes, anti-oncogenes, among others) should be extensively studied and considered in the development of each of the neoplasia types of the human organism. On analysing the actuarial curves and survival curves of the different types of neoplasias, initially, we can see that some organs manifest neoplasias more frequently than others. Many considerations can be made about this fact. These include exposure of these organs to environmental agents (irritants, mutagenics, radioactivity), technical facility of approaching the organ for diagnosis, the time delay for the appearance of the symptoms and even intrinsic factors of these organs and the cellular predisposition to the development of neoplasias, whether benign or malignant.

Thus, tumours that involve the heart muscle constitute a group of very rare neoplasias, with diagnosis being made either clinically or by necropsy. Until recently, the majority of the diagnoses of heart neoplasias were made by examinations during necropsy [1]. With the advent, over the last decades, of new complementary methods of diagnosis, the number of patients presenting with symptoms of heart neoplasias has increased, making it possible to surgically treated some cases. Non-invasive and invasive methods have been utilised with low morbidity and high efficacy in the diagnosis of this pathology, supplying clinical (chemotherapy) or surgical (total resection) treatment of myocardial tumours. Such diagnostic methods, both invasive and non-invasive, have become extremely import in the diagnosis of heart tumours [2,3]. This fact can be confirmed by analysing the signs and symptoms that are manifested in heart tumour patients. In the great majority, the symptoms of heart and pericardial sac tumours are inherent in numerous formas de doença não disseminada. O diagnóstico tardio implica em altas taxas de morbidade e mortalidade, associada ou não ao tratamento cirúrgico. Os autores descrevem caso de paciente com melanoma localizado no ventrículo direito, a abordagem diagnóstica e terapêutica realizada, comparandoas com os dados da literatura. A revisão da literatura é inconclusiva quanto ao tratamento de escolha dos tumores malignos do músculo cardíaco (primários ou metastáticos). Os autores sugerem a realização de estudos retrospectivos com metanálise na tentativa de estabelecer critérios diagnósticos e terapêuticos para os tumores malignos do coração, devido à pequena incidência desta doença.

Descritores: Neoplasias cardíacas. Melanoma. Mixoma. Arritmia. Procedimentos cirúrgicos cardíacos.

other non-neoplastic pathologies of the cardiovascular system. These include precordial pain with or without systemic hemodynamic alterations where coronary failure should be considered. Arrhythmias, alterations in the conduction of heart stimuli, foci of ectopic cardiac stimulation, conduction disorders of the Hiss-Purkinje system and its branches, among numerous other signs and symptoms. All these can be attributed to a large number of acquired heart diseases, including tumours (primary or secondary of the heart and pericardial sac) [1]. Several details of the clinical history and of the physical examination of these patients need to be considered so that the diagnosis can be established in the correct manner and the correct treatment proposed. It is important to stress the role of complementary methods when looking for differential diagnosis among these pathologies. The 1- and 2 dimensional echocardiography with studies of the intracavitary blood flow, using transthoracic or oesophageal echocardiography is an important method in the evaluation of heart tumours. A greater diagnostic accuracy is attained when, for example, thoracic and mediastinal computed tomography are associated. The echocardiography acquires an important role in the evaluation of heart tumours and their intracardiac relationships. The size of the tumour, location, focus, involvement of valvar leaflets, intracavitary obstruction of blood flow, signs of invasion of heart muscle can all be examined by this method. The association with thoracic computed tomography or with magnetic resonance (more recently with angioresonance) provide very important information about the relationships between the heart affected by neoplasms and the surrounding structures. The tumour size, intra or extracardiac position, invasion of the pericardium or neighbouring structures, the organ in which the tumour originated (mediastinal or lung tumour with invasion of the pericardial sac and/or the heart), analysis of the tumour resectability, possibility of metastasis, possibility of metastatic neoplasm from other organs are important 
information that can be achieved with an association of these methods [4].

In relation to invasive methods including heart catheterism, cardiovascular angiography and the possibility of endovascular biopsy, we can stress their importance in pre-operative diagnosis of malignant heart neoplasias (primary or metastatic) and also in the differential diagnosis with pathologies that involve the cardiovascular system more frequently than neoplasms [2].

This review of literature, focusing on primary or metastatic malignant heart tumours is utilised for the description and discussion about the incidence and prevalence of intracardiac tumours, their diagnostic criteria and prognosis, considerations about the treatment methods and about complimentary examinations necessary for the presumptive and definitive diagnosis.

\section{DISCUSSION}

For educational reasons and to simplify we can group the tumours that involve the heart and the pericardial sac in primary and secondary tumours.

Primary heart tumours can be subdivided in benign and malignant tumours Figure 1.

Primary tumours $\left\{\begin{array}{l}\text { Benign }\left\{\begin{array}{l}\text { Myxoma } \\ \text { Rhabdomyoma } \\ \text { Fibroma } \\ \text { Lipoma } \\ \text { Angioma } \\ \text { Papillary heart tumours }\end{array}\right. \\ \text { Malignant } \begin{array}{l}\text { Rhabdomyosarcoma } \\ \text { Mesenchymoma } \\ \text { Neurosarcoma } \\ \text { Fusiform cell tumours } \\ \text { Lymphosarcoma } \\ \text { Malignant heart hemangioma }\end{array}\end{array}\right.$

Secondary tumours $\begin{cases}\text { metastatic } & \left(\begin{array}{l}\text { hematogenic } \\ \text { lymphatic }\end{array}\right. \\ \text { by contiguity } & \begin{array}{l}\text { mediastinal tumour } \\ \text { lung tumour } \\ \text { oesophageal or cardia tumour }\end{array}\end{cases}$

Fig. 1 - Classification of heart tumours
Among the benign tumours, the myxomas are the most common. According some authors, there is one primary heart tumour for every 5,000 non-selected necropsies [1]. The incidence of heart tumours is less than $0.2 \%$ of the tumours that can be found in the organism. The myxomas represent around half the benign heart tumours. They can occur in any age range, however they are more frequent in the $40 \mathrm{~s}$ and 50s. They are more commonly found in the left atrium, in contact with the mitral valve, sometimes pedunculated to one of its leaflets (Figure 2). Myxomas of the right atrium, obstructing the outflow tract of the right ventricle, tumoral soft emboli to the lungs and stenosis of the pulmonary valve have also been described [1,5-7].

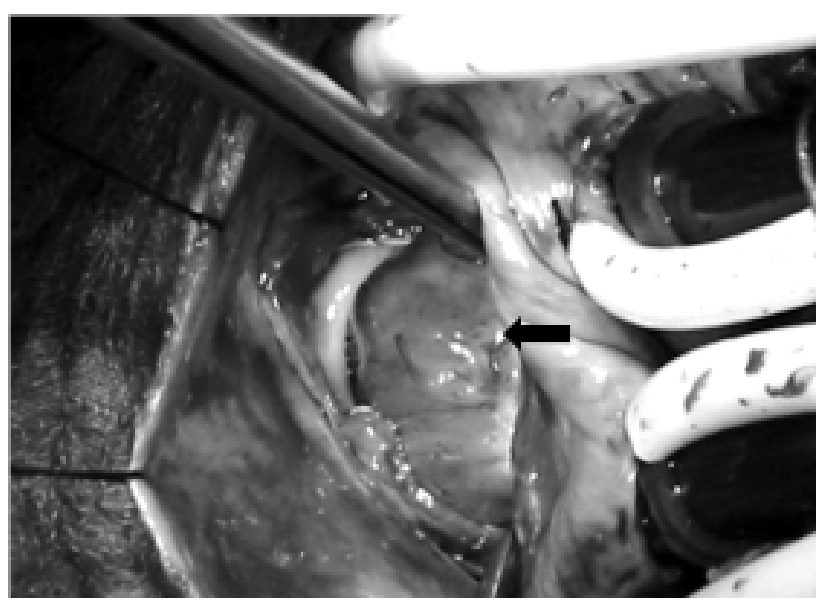

Fig. 2 - Myxoma of the left atrium (arrow). Young male patient admitted with acute oedema of the lung. Examination revealed a large tumour in the left atrium. Intraoperative photograph: right anterolateral thoracotomy, opening of the left atrium and exeresis of the tumour pedunculated on the interatrial septum.

Among the primary malignant heart tumours, the most common histologic type is represented by sarcomas of the heart muscle (Figure 3). The rhabdomyosarcomas are found in the right atrium and the right ventricle in around $40 \%$ of the cases of primary malignant heart neoplasms. As they have a potential of dissemination and local invasion, they can rapidly invade the right ventricle, vena cavas, interventricular septum and the left heart chambers. Alterations of the heart rhythm, arrhythmia and blocks of the conduction of electrical stimuli of the Hiss-Purkinje system are more common in this type of neoplasm than in myxomas and in the metastatic tumours to the heart [8-11].

FABRICIUS et al. [9] reported a case of a patient who rapidly developed heart insufficiency owing to leiomyosarcoma of the left atrium. The patient was urgently 
submitted to surgical treatment. During the operative procedure, a large tumour originating in the left atrium and extending to both of the pulmonary veins was identified and resected. Histologically the tumour demonstrated epithelial lineage with a strong immunoexpression of desmin and actin. Six months after the operation the patient presented with relapse of the tumour evolving to death.

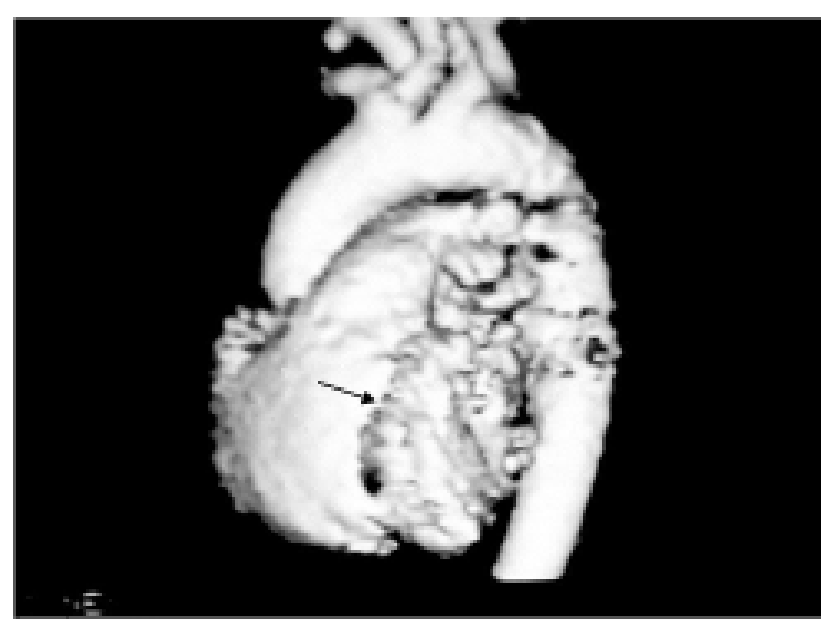

Fig. 3 - Angioresonance of a patient with sarcoma in the left ventricle. Note the infiltrative aspect and irregularity of the wall of the left ventricle (arrow).

FUKUOKA et al. [10] reported the diagnosis of heart leiomyosarcoma in a patient who had previously been submitted to resection of neoplasms of the thyroid and the lower lobe of the left lung. According to the authors, an anatomicopathological study revealed an independent nature among the histologic types of the three tumours. They reported the appearance of leiomyosarcoma of the left atrium in a 63-year-old patient and presented a brief review of the literature about primary malignant heart tumours.

KWOK \& HUNT [12] described a study performed with patients who underwent heart transplantation and reported this fact arising from the primary tumours of the heart muscle. According to the authors, the immunosuppression that these patients are submitted to might be a factor involved in heart carcinogenesis, associated with the chronic pathologies that cause the patient to undergo transplantation.

UCHIKAWA et al. [7] reported a form of very rare heart neoplasm, the malignant fibrous histiocytoma, in a 50-yearold patient admitted for surgical treatment of congestive heart insufficiency caused by the presence of a heart tumour. According to the authors, the preoperative examinations demonstrated the presence of a large tumour in the septal wall, posterior of the left atrium. The tumour was completely removed and the wall of the atrium was reconstructed with a pericardium graft. The histopathologic diagnosis concluded malignant fibrous histiocytoma. The patient presented with a bad postoperative evolution with dissemination of the tumour.

CHAN et al. [2] reported the efficacy of the endocardial biopsy using a transseptal approach. They described the case of a sarcoma in the left atrium that was diagnosed by transseptal endocardial biopsy guided by echocardiography.

MORIN et al. [13] described myxoid leiomyosarcoma of the left atrium as an extremely rare neoplasm and compared it with myxoma of the left atrium. According to the authors, this type is a rare malignant tumour that generally develops in the left atrium, contrary to the descriptions of other authors who reported that the sarcomas are normally evidenced in the right heart chambers. The authors report the case of a 53-year-old patient with symptoms of mitral valve stenosis and severe pulmonary hypertension. Echocardiography and angiography revealed a tumour in the left atrium, initially interpreted as myxoma. The tumour was resected and histopathologic, immunohistochemical and electronic microscopic studies identified the lineage of the tumour. No additional treatment such as radiotherapy was performed, according to the authors, owing to the severe pulmonary hypertension of the patient. Routine tests performed two months after the operation revealed the tumour had relapsed.

BRUNNER LA ROCCA et al. [8] reported the case of a patient who presented with a mass in the left atrium, of which resection was not possible for two reasons: the inflammatory pseudotumour aspect and the atypia cells suggesting a diagnosis of heart muscle sarcoma. Immunohistochemical examinations including PCNA, MIB1/Ki67, bcl-2 positive, p53 negative and $\mathrm{nm} 23$ lost focus, suggested the malignancy of the tumour, but did not confirm its histological lineage. The patient was accompanied for 28 months, after which presented with metastasis in the spinal column and new tumour growth. The patient was submitted to radiotherapy, according to the authors, he presented with a favourable evolution over 15 months.

WIPPERMANN et al. [11] reported a radical re-operation for the treatment of leiomyosarcoma of the heart muscle. According to the authors, leiomyosarcoma of the heart correspond to less than $0.2 \%$ of all heart tumours and in cases of large and invasive tumours, the possibility of heart transplantation should be contemplated. They reported a successful re-operation of a patient submitted to resection of a heart leiomyosarcoma two years previously. According to the authors, there is still a possibility of relapse after heart transplantation.

TODA et al. [14] described the diagnosis and treatment of a 16-year-old submitted to resection of a malignant fibrous histiocytoma of the heart. According to the authors, the patient presented with severe dyspnea at admission and 
complementary examinations revealed a tumour of $10 \mathrm{~cm}$ in diameter located in the left atrium. The patient was submitted to complete resection of the tumour and the anatomicopathological examination identified it as a malignant histiocytoma. No complementary treatment, such as radiotherapy or chemotherapy, was indicated and there was no evidence of metastasis or relapse of the tumour nine months after the procedure. Also, according to the authors, there are only 42 cases of malignant fibrous histiocytoma described in the literature, confirming the rarity of this type of neoplasm.

Metastatic tumours to the heart and pericardial sac present with a higher incidence than the primitive tumours of the heart muscle. Metastatic tumours to the heart can be found in $60 \%$ of necropsies involving malignant tumours. Carcinomas, among which are carcinomas of the lung and sarcomas in general can cause metastasis to the heart and its surrounding structures. Dissemination via the lymphatic system or by contiguity is responsible for the presence of metastasis in the pericardium and myocardium, however it is rare in the endocardium.

Similar to carcinomas, their metastases from other tumours of the endothelial lineage also principally affect the myocardium. Among these, malignant melanoma is responsible for about $44 \%$ of the metastasis to the heart and pericardium [1]. The clinical symptoms may be initially scarce. On the other hand, rarely the patient develops with cardiac insufficiency, as in the cases of epithelial endovascular tumours. The clinical manifestations, represented by disorders in the conduction of heart electrical stimuli and arrhythmia, can occur in up to $10 \%$ of the cases. The metastasis of melanomas to the pericardium sac may be responsible for the accumulation of liquid within the serosa and for heart tamponade as the initial diagnosis of the pathology.

Several authors $[2,6,15]$ described the high sensitivity and specificity for the diagnosis of the intracardiac masses that the echocardiogram can provide. The also describe the necessity of an association between this method of imaging and endovascular biopsy, either by the transseptal approach or directly on the intracardiac mass.

According to GINDEA et al. [4] metastatic malignant melanomas to the heart have a high incidence and may occur in up to $64 \%$ of the necropsies of patients who die owing to this neoplasm. The presence of cardiac metastasis in associated, in these patients, to a great spread of the disease involving multiple organs. The authors describe the presence of a pleomorphic malignant tumour obliterating both the ventricular chambers, whose diagnosis of malignant melanoma was made by immunohistochemical evaluation. According to the authors, the patient was admitted complaining of progressive dyspnea over a 30-day period before the consultation. As well as the tachycardia and the objective dyspnea, only a slight systolic murmur was audible in the precordial region. One year before the patient had been submitted to resection of a melanoma in the dorsal region. The chest radiograph did not demonstrate alterations and the electrocardiogram revealed a sinusal signal, delay in the intraventricular conduction of the atrial stimulus and non-specific alterations of the ST-segment of the T-wave. The echocardiogram revealed an extensive intramyocardial mass that exerted compression on the right and left ventricular chambers. Magnetic nuclear resonance and endovascular biopsy were important examinations in the determination of the diagnosis and treatment of this patient, according to the authors. They suggest that the magnetic resonance should be utilised, supplying important information of the involvement of the heart and the intrathoracic structures, mainly when there are technical difficulties to perform the echocardiogram.

ROSÁRIO et al. [15] reported the occurrence of heart metastasis of an ocular melanoma in an 84-year-old patient. According to the authors, cardiac tumours generally represent causes of symptoms such as syncope by obstruction and difficulties in the blood flow through the left ventricle. They reported that malignant melanomas are tumours capable of causing this aspect, although few cases have been described in the literature in which the involvement of the endocardium by tumours is the origin of all the symptoms. They described the presence of a $6.2 \mathrm{x}$ $3.2-\mathrm{cm}$ floating but non-homogenous mass occupying nearly all the left ventricular chamber, detectable by transthoracic echocardiography and that it was propelled by the blood flow through the aortic valve at every systole. On being submitted to left ventriculotomy a dark mass pedunculated to the papillary muscles was removed. The patient presented with a fatal mediastinal haemorrhage in the postoperative period. For the authors, the primary neoplasms of the heart are extremely rare observed in from 0.0017 and $0.28 \%$ of necropsies. Metastasis to the heart can be seen with a higher frequency, occurring in from 1.5 to $21 \%$ of the patients with neoplasms. In this group, the melanomas correspond to up to $65 \%$ of the cardiac metastasis in patients with disseminated neoplasms. According to the report by the authors, there are only 16 cases of metastatic cutaneous melanoma published as a pedunculated intracardiac mass [15-17]. Typically the cardiac involvement of metastatic melanoma is related to spreading to the pericardial sac and myocardium. In this report, the authors describe the first case of metastasis of melanoma to the endocardium, with the primary tumour identified in the ocular globe. They also suggested the possibility of endocardial biopsy and preoperative chemotherapy to reduce the size of the intracardiac mass. 
GAUDREÉ et al. [16] reported the case of a 70-year-old patient who had previously been submitted to enucleation of the left eye owing to a melanoma three years previously. They described the presence of two intracardiac masses in the right atrium and the left ventricle, whose resection and biopsy demonstrated they were malignant melanoma. The patient was submitted to chemotherapy and observed, remaining in a good general state for the five years after diagnosis. The authors discuss the possibility of metastasis of ocular melanoma to the heart, as well as the possibility of the primary tumour of the heart, with spontaneous relapse and cure using surgical resection without subsequent complementary treatment.

WIKBERG et al. [18] described in a reports new aspects of melanocortins and their tissue receptors. The knowledge of melanocortins, of their receptors, the identification of five receptors of melanocortin and the discovery of two endogen antagonists for these receptors have awakened a great interest of investigators in this field. The authors discuss the pharmacology, physiology and molecular biology mechanisms of the melanocortins and their receptors. In particular, they reviewed the relationship between the melanocortins and the immunological system, paying special attention to the cardiovascular system.

KAZA et al. [19] described the possibility of resection of intracardiac tumours utilising cardiopulmonary bypass, aortotomy and introduction of video-surgery equipment through the aortotomy and the aortic valve, enabling direct ample vision of intracardiac masses. They described the efficacy of the method utilised for the resection of pedunculated tumours in the interventricular septum viewed by endoscopy (mainly in cases in which direct vision of the tumour is hampered) with good results and without relapse in the heart muscle.

Cardiac neoplasms have a very low incidence, whether primary or metastatic when compared with neoplasms that involve other organs, for example, the beasts, lungs, prostate and intestine. Primary neoplasms of the heart muscle and of the intracardiac structures represent a rarity varying in incidence as reported in the literature of between 0.0017 and $0.28 \%$. The main histological types of primary heart tumours are the myxomas, fibromyxomas and the sarcomas. Direct invasion by continuity, by contiguity or by lymphatic or hematogenic dissemination of the carcinomas and melanomas can involve the heart tissues in 6 to $10 \%$ of the patients who present with this type of tumour. Carcinomas or adenocarcinomas that invade the heart and surrounding structures frequently originate in the adjacent pulmonary parenchyma. A similar number of cases of metastatic tumours to the heart are represented by melanoma. Among the metastatic tumours to the myocardium, 30 to $65 \%$ of the cases are melanomas [1].
Statistically, the primary tumours of the heart more frequently develop in the left heart chambers, as for example, the rhabdomyosarcomas and the myxomas of the left atrium. There may be invasion and involvement of the right heart chambers at the moment of diagnosis or the appearance of the first symptoms $[2,5,9,13-15,20]$

Additionally, metastatic tumours to the heart occur more commonly in the pericardium (lymphatic dissemination) and the right chambers (theory of hematogenic dissemination).

In patients in whom there is dissemination of a tumour to the pericardium, the initial and predominant signs and symptoms are related to the presence of neoplastic secretion around the heart. Thus, they are related to great pericardial strokes and heart tamponade [20].

Considering the primary or metastatic tumours that involve the heart muscle, the main form of manifestation is arrhythmia and disorders of the conduction of the electrical stimulation system of the heart. Atrial fibrillations, atrial flutter, isolated or frequent ventricular extrasystoles, occlusion of the right branch (and of its divisions) are phenomenon frequently observed in these patients. Signs and symptoms of congestive heart failure are reported and associated to heart tumours that involve the right heart chambers in particular. In truth, they manifest themselves with symptoms of blood flow obstruction through the right ventricle, requiring a differential diagnosis with right ventricle infarction, thrombosis of the suprahepatic veins, thrombosis of the superior vena cava, mediastinal tumours and pulmonary stenosis, among others $[1,3,11,16]$.

Several other signs and symptoms may be associated in patients with neoplasms of the heart at a lesser frequency. These include thoracic or precordial pain, dyspnea on effort, fainting, dizziness, syncope and convulsions. It is important to stress that these non-specific symptoms, in patients with heart tumours, are much more frequent in other nonneoplastic pathologies of the cardiovascular system, among which are arrhythmia, coronary insufficiency and valvar pathologies and acute aortic diseases.

Arrhythmias are the most common form of manifestations of primary and metastatic heart tumours. The pedunculated tumours can be more arrhythmogenic than the sessile tumours in the initial phases of the disease [15].

The other signs and symptoms might be non-specific and the differential diagnosis with other cardiopulmonary pathologies is important.

The physical examination and laboratorial examinations can be non-specific and inconclusive.

The chest radiograph evidences, in the majority of cases, an increase in the heart area, however it is unlikely to present a clinical suspicion of a neoplasm of the myocardium. Signs of enlarged right and left heart chambers may be seen in dilated myocardiopathies, with arrhythmia or not. 
Radiographic signs of heart tamponade are signs that most commonly lead to clinical suspicion of neoplasms, even in the pericardium. Around 60 to $70 \%$ of diagnosed pericardial effusions are due to pericardial tuberculosis. Between 20 and $25 \%$ of cases prove to have neoplastic aetiologies from pericardial secretions. Other causes of increase of the cardiac area, owing to a fluid increase in the pericardium, include systemic lupus erythematosus, hypothyroidism, dermato-polyserositis in general, malnutrition, chronic renal failure, hepatic insufficiency and acute infectious processes in immunosuppressed or transplant patients.

The presence of alterations in the heartbeat or the condunction of stimuli, detected by electrocardiogram, can also be non-specific and suggest several differential diagnosis (figure 4).

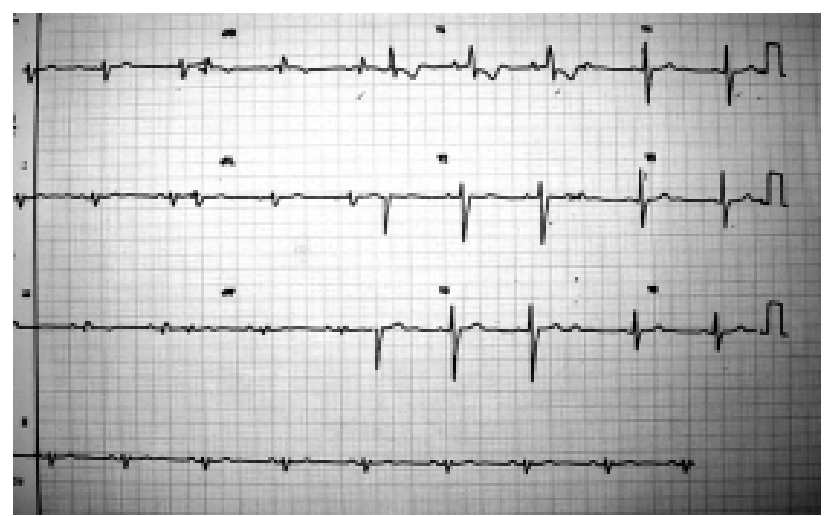

Fig. 4 - Electrocardiograph of a patient with melanoma of the right ventricle. Note the non-specificity of the alterations: sinusal rhythm; PR $=0.16 \mathrm{~ms} ; \mathrm{QRS}=30^{\circ}$; non-specific alterations of the ventricular repolarization on the anterior wall (" $R$ " ample and " $T$ " negative at V1).

Doppler echocardiogram constitutes the examination with the greatest sensitivity and specificity for the diagnosis of intracardiac masses, mainly the atrial myxomas $[5,6,9,16]$. The presence of pedunculated or sessile vegetating lesions on one of the valvar leaflets or on the valve apparatus, the absence of infectious signs and symptoms and frequently associated with arrhythmia, can lead to the diagnosis of heart tumour. Obstruction of the blood flow at the site of the tumour, related to intracavitary structures, involvement of the myocardium and pericardium are all data which can be obtained with transthoracic or transesophageal Doppler echocardiography.

Other imaging techniques, such as computed tomography and thoracic magnetic resonance (angioresonance) may be useful in the evaluation of surrounding structures, determining if the tumour may have an origin from intrathoracic organs or not. Pulmonary neoplasms, thymic carcinomas and lymphomas can be evaluated by these methods [4]. The malignant neoplasms of the thymus gland (stage III thymomas, according to MASAOKA et al.[21]) and the inter-thoracic lymphomas, when they are not diagnosed in the initial phase can compress or directly invade the neighbouring mediastinal structures, such as the heart, the great vessels, lungs and trachea. Generally the clinical signs and symptoms are related to compression syndrome of the superior vena cava. The diagnosis can be made by transthoracic biopsy guided by computed chest tomography (Figure 5).

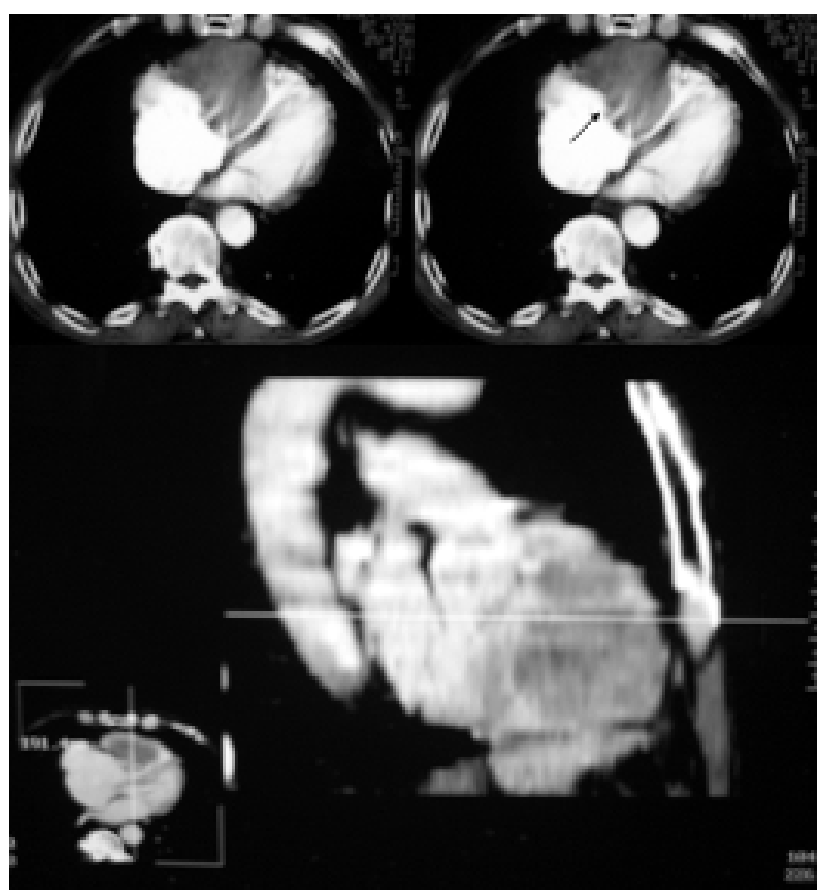

Fig. 5 - Computed chest tomography. Note the presence of an extensive injury - hypodense with well-defined limits involving the anterior wall of the heart (arrow).

In a similar manner, the renal tumours (Wilm's tumours) and those of the suprarenal glands can also involve the cardiovascular system. Invasion of the renal veins by the cited neoplasms can cause "neoplastic thrombi" that invade the right atrium through the inferior vena cava. "Neoplastic emboli" can involve both lungs (metastasis) and direct invasion of the heart muscle by these neoplasms infrequently occurs.

Even in cases of primary or metastatic heart tumours, tomography and resonance can supply important information. The tumour aspect, the presence of areas with different attenuation coefficients, the tumour size, involved heart chambers, involvement of the atrial or ventricular septa, involvement of the aorta or the pulmonary artery, the number of foci of the tumour within the heart can be shown by these examinations. 
Heart catheterism can be indicated, associated or not with myocardial or tumoral endovascular biopsy [2]. There are no published reports related to criteria for the indication of biopsies of heart tumours, mainly due to the extremely low incidence of this pathology. In our opinion, the performing of endovascular biopsies should be made in cases in which the imaging methods demonstrate the irresectability of the heart tumour and the absence of involvement of other organs. Thus, determination of the histological type of the heart tumour is important to guide treatment (Figure 6).

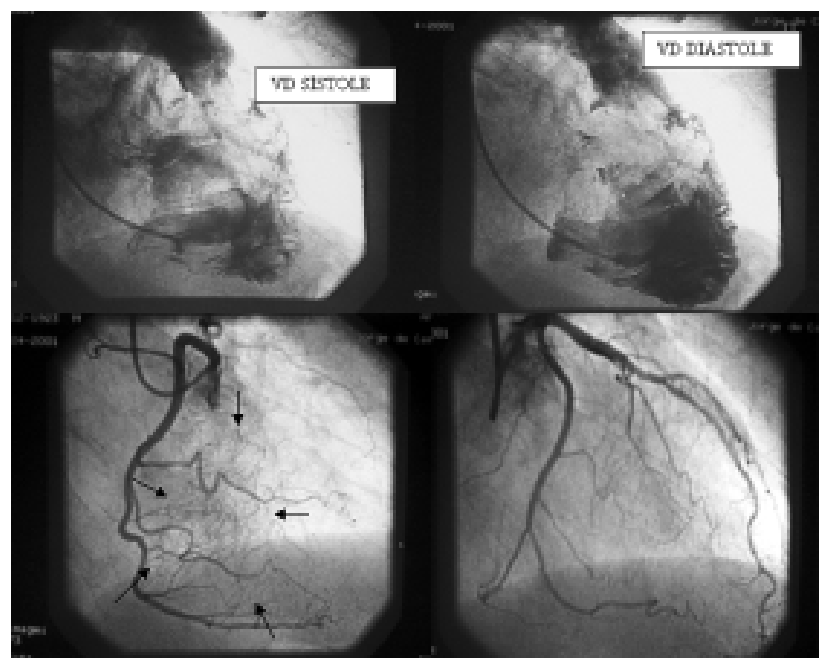

Fig. 6 - Coronary cineangiography. Note the presence of a great failure in the filling of the right ventricle (compare the images of the right ventricle systole and diastole), Determinant of severe restriction of diastolic filling of the right ventricle. Note, also, an area of hyper-vascularization, with predominance of neo-formed vessels from the right coronary artery to irrigate the tumour (arrows).

In cases where there is suspicion of myxoma of the left atrium or intramural thrombi, the endovascular biopsy is contraindicated by the risk of emboli and of dissemination of the neoplasm to other organs. Surgical treatment would be the choice therapeutic method.

Recent studies with antigens and histocompatibility and with melanocortins and their receptors may report the tropism of the cells of melanoma by myocytes of the heart $[18,22]$. This would explain the high incidence of metastasis of melanoma to the myocardium in patients with systemic dissemination of melanomas. The "immuno-attraction" between melanoma cells and the heart muscle may also be the explanation for the fact that patients operated for ocular or skin melanoma, remain free of the neoplastic disease at the primary site but present with isolated "metastasis of melanoma" to the myocardium. Criteria can be adopted for the identification of a risk group when aged patients submitted to resection of skin or ocular globe melanoma and who present with arrhythmia of an unknown cause are analysed.

The diagnosis of melanoma only in the myocardium might suggest the presence of a very small undetected tumour in another organ or in mucous membranes. There is no evidence in publications that myocardial cells can acquire malignant behaviour and synthesis of melanin. Studies performed with totipotent cells and implants of these in the heart muscle may elucidate this fact in the future [18].

In the case of small confined, pedunculated or sessile melanomas, which can be resected, surgical treatment should be indicated. Surgical resection of intracardiac tumours, such as myxomas, has a low morbidity and mortality when compared to tumours that infiltrate the heart walls, such as melanomas and sarcomas (Figure 7).

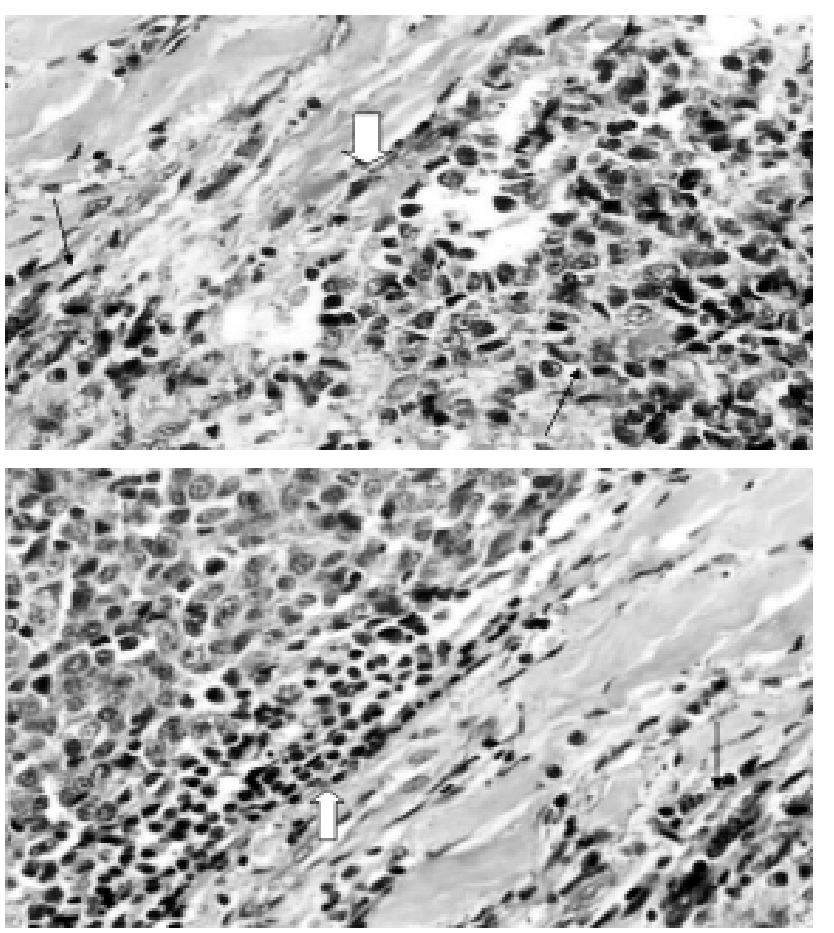

Fig. 7 - Microscopic aspect of tumour invading cardiac muscle fibres. Note the infiltrative aspect of the tumour, the invasion and destruction of the myocardial fibres by the neoplasm (large white arrows) and the presence of a great quantity of melanin (black and thin arrows).

The age range of patients, the fragility of the organs and tissues, the risks inherent in heart surgery and cardiopulmonary bypass and the uncertain behaviour and aggressiveness of melanomas are determining factors of 
high mortality of these patients, both in the immediate and late postoperative periods $[14,16]$.

There are also no published reports, owing to the extremely low incidence, about the chemotherapeutic or radiotherapeutic treatments of heart melanomas. Thus, it is not possible to determine the impact of palliative treatment on the survival of these patients. Patients with disseminated melanoma and with heart metastasis present with an extremely low survival rate, both with and without treatment.

We can conclude that the melanomas and other heart tumours can manifest themselves through arrhythmia and rhythm disorders, they can cause obstruction in the blood flow through the heart. Their incidence is extremely low, however the aggressiveness of the tumoral cells and the potential of dissemination determine a high mortality rate. Non-specific diagnosis of the intracardiac tumoral mass can be made by conventional imaging methods, such as echocardiography, computed tomography and chest magnetic resonance. More rarely heart catheterism can be indicated in cases for endovascular biopsies of the mass. Treatment should preferentially be surgical, however, the conditions of the heart and tumour, associated with the fragility of the involved organs and the age of these patients, are factors that determine a high mortality rate (Figure 8).

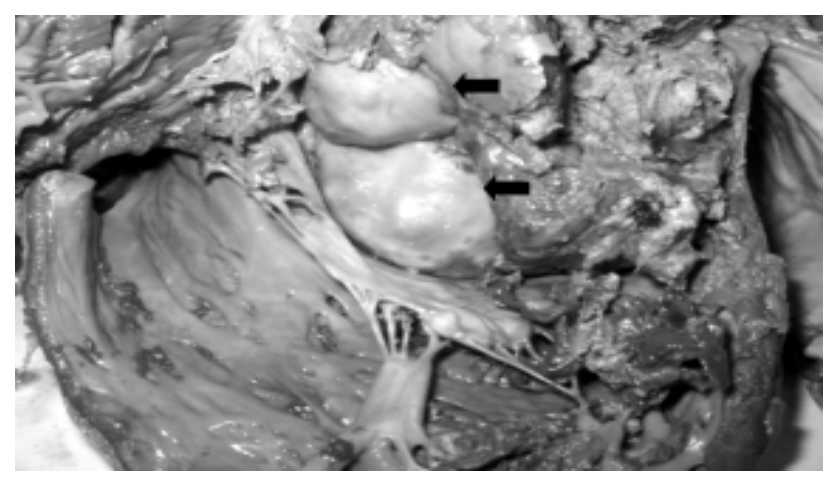

Fig. 8 - Malignant thymoma invading mediastinal structures and the heart. Note the presence of a tumoral mass (arrow) with a nacre-coloured aspect completely obliterating the tricuspid valve. Photograph the necropsy of a young patient with symptoms of compression of the superior vena cava and heart "tamponade".

In light of recent advances presented by immunohistochemistry, genetics and molecular biology we suggest that multiple centre studies and metanalysis should be used, aiming at grouping reported cases, providing studies to determine the best manner to conduct treatment of these patients.

\section{BIBLIOGRAPHIC REFERENCES}

1. Dallan LAO, Pomerantzeff PMA, Stolf NAG. Tumores do coração. In: Raia AA, Zerbini EJ, editores. Clínica Cirúrgica Alípio Corrêa Neto. São Paulo: Sarvier; 1988. p 791-7.

2. Chan KL, Veinot J, Leach A, Bedard P, Smith S, Marquis JF. Diagnosis of left atrial sarcoma by transvenous endocardial biopsy. Can J Cardiol 2001; 17:206-8.

3. Leão LEV, Giudice R, Yamashita HK, Conforti CA, Crotti PLR, Oliveira R. Thoracoscopic relief of symptomatic lipomatous hypertrophy of atrial septum. In: The $2^{\text {nd }}$ minimally invasive thoracic surgery interest group. International Symposium: Controversies in cardiothoracic surgery;1998;Hong Kong (China). Anais. Hong Kong (China):Minimally Invasive Thoracic Surgery Interest Group; 1998. p47.

4. Gindea AJ, Steele P, Rumancik WM, Culubret M, Feiner H, Sanger JJ et al. Biventricular cavity obliteration by metastatic malignant melanoma: role of magnetic resonance imaging in the diagnosis. Am Heart J 1987; 114:1249-53.

5. Kaynak K, Besirli K, Arslan C, Ozgüroglu M, Oz B. Metastatic cardiac myxoma. Ann Thorac Surg 2001; 72:623-5.

6. Sadeghi N, Sadeghi S, Karimi A. Mitral valve recurrence of a left atrial myxoma. Eur J Cardiothorac Surg 2002; 21:568-73.

7. Uchikawa S, Nakajima M, Hirayama T, Misumi H, Shimokawa Y, Kamio T. A case of a left atrial primary malignant fibrous histiocytoma. Kyobu Geka 2001; 54:77-9.

8. Brunner-La Rocca HP, Vogt PR, Burke AP, Schneider J, Jenni R, Turina MI. A primary cardiac sarcoma with unusual histology and clinical course.Ann Thorac Surg 2001; 71:1675-7.

9. Fabricius AM, Autschbach R, Lochhaas L, Brose S, Mohr FW. Primary left-atrial leiomyosarcoma. Thorac Cardiovasc Surg 2000; 48:306-8

10. Fukuoka M, Hagiwara M, Shimoshige S, Hirata A, Adachi T, Komura $\mathrm{H}$ et al. Primary leiomyosarcoma of the heart subsequent to double carcinomas of the thyroid and lung. Heart Vessels 2000; 15:100-2.

11. Wippermann J, Albers JM, Brandes H, Wahlers T. Redoextirpation of a cardiac leiomyosarcoma to avoid transplantation. Thorac Cardiovasc Surg 2002; 50:62-3.

12. Kwok BW, Hunt SA. Neoplasia after heart transplantation. Cardiol Rev 2000; 8:256-9.

13. Morin JE, Rahal DP, Hüttner I. Myxoid leiomyosarcoma of the left atrium: a rare malignancy of the heart and its comparison with atrial mixoma.Can J Cardiol 2001; 17:331-6. 
14. Toda R, Yotsumoto G, Masuda H, Sakata R, Umekita Y. Surgical treatment of malignant fibrous histiocytoma in the left atrium and pulmonary veins: report of a case. Surg. Today $2002 ; 32: 270-3$.

15. Rosario RT, DiMaio DJ, Lapham RL, Sweeney M, Smalling $\mathrm{R}$, Barasch E. Metastatic ocular melanoma to the left ventricle inducing near-syncope attacks in an 84-year-old woman. Chest 2000; 118:551-3

16. Gaudrée L, Chabrun A, Corbi P, Levillain P, Herpin D. [Intracardiac metastasis of malignant melanoma. Literature review and case report]. Arch Mal Coeur Vaiss 2000; 93:1339-42.

17. Gutierrez PS, Mansur AJ. Metastatic neoplasia involving a mitral bioprosthesis. Lancet Oncol 2001; 2:232.
18. Wikberg JE, Muceniece R, Mandrika I, Prusis P, Lindblom J, Post $\mathrm{C}$ et al. New aspects on the melanocortins and their receptors. Pharmacol Res 2000; 42:393-420.

19. Kaza AK, Buchanan SA, Parrino GP, Fiser SM, Long SM, Tribble CG. Cardioscope-assisted escision of a left ventricular tumor: a case report. Heart Surg Forum 2002; 5:75-6.

20. Carlin BW, Dianzumba S, Joyner CR. Metastases to the right ventricle. Chest 1988; 93:1320.

21. Masaoka A, Monden Y, Nakahara K, Tanioka T. Follow-up study of thymomas with special reference to their clinical stages. Cancer 1981; 48:2485-92.

22. Carosella ED. HLA-G: fetomaternal tolerance. C R Acad Sci III 2000; 323:675-80. 